\title{
RISK ASSESSMENT MODEL BASED ON FUZZY LOGIC FOR RESIDENTIAL BUILDINGS
}

\author{
Namdeo HEDAOO ${ }^{1 *}$, Amey PAWAR ${ }^{1}$
}

\begin{abstract}
Risk is involved in every construction project. Residential building construction projects comprise a variety of risks and are more likely to be affected due to their difficulty and many operations and threats. The study aims to identify the various risk elements and their effect on construction projects of residential buildings using a fuzzy approach with the help of MATLAB software. This study includes 60 risk factors recognised through an expert opinion and literature review. These factors are categorised into 7 major groups, i.e., construction, project manager, architect/consultant, contractor, owner, resources, and external environment-specific risk factors. A questionnaire was prepared and sent using emails based on the identified risk factors to be filled out by construction industry professionals in India and by conducting in-person interviews. Based on the risk severities obtained from the fuzzy model, the top 10 risk factors have been considered. As a result, for identified top severe risk factors, a significant risk response strategy was implemented.
\end{abstract}

\section{Address}

1 Dept. of Civil Engineering, Government College of Engineering, Pune, India.

* Corresponding author: nah.civil@coep.ac.in

\section{Key words}

- Risk assessment,

- Construction industry,

- Fuzzy set theory,

- Fuzzy logic.

\section{INTRODUCTION}

India is a nation that is urbanising rapidly. The urban population has grown from 290 million in 2001 to an estimated 340 million in 2008, with 590 million expected by 2030 . Real estate and homeownership grew by 5.6 percent in 2012-2013, with a 5.9 percent share of India's GDP. Each rupee invested in the housing and construction is expected to add 78 pairs of rupees to the GDP. However, the growth of infrastructure and the positive efficiency of Indian residential construction projects have not been encouraging expectations. Residential buildings, including the affordable housing sector, are expected to boost India's demand for real estate. The requirement of improved infrastructure is growing day by day in huge quantities; hence, the size and volume of residential building projects in India have increased to a great extent with highly cost-intensive projects, making construction tasks increasingly challenging to manage, govern, and deliver with the desired efficacy, timeline, and effectiveness. Risk management has become more vital for the completion of residential building construction projects due to the increased complexity and the use of modern equipment and techniques.

Unpredictable events, which may significantly impact a company, are likely to be faced by all organisations. The construction of residential buildings is also vulnerable to uncertainties, which include a different range of risks and complexity. The recent tendency in residential construction projects is for size of a project to get larger, which raises the project's complexity, by their resulting in a higher level of risk and uncertainty. In most residential building projects, the risk is ignored.

Consequently, many major residential construction projects in India struggle to meet their expected deadlines and cost goals successfully, resulting in losses for contractors and owners. These risks may affect an organisation's expected financial outcome, resulting in massive losses by the organisation. International standards (BS ISO 31000, 2018) suggest that each company create, adopt and continually enhance a risk management system and incorporate it into its overall governance, planning and strategy framework. The study aims to find the essential risk factors im- 
pacting the easy completion of residential building construction projects in India. A fuzzy logic toolbox in MATLAB software was used for analysing the risk factors. The findings of the study would be helpful for project managers to assess and handle risks in residential building construction projects with the help of a model developed in the fuzzy logic toolbox, make suggestions on the methods of risk evaluation and implement effective risk response strategies for the most severe risks identified by the fuzzy assessment model for the smooth completion of a project.

\subsection{Why use fuzzy logic?}

In today's world, safety and reliability are significant considerations. Modern equipment and systems should fulfil technical, safety, and environmental protection standards. Personal harm or death, mission deterioration, technological property damage, or destruction are all possible outcomes of taking risks, which are defined as the result of combining the likelihood and the consequence of a particular hazard occurring. We need scientific perspectives to help make decisions, and we occasionally have to consider moral issues. One of them is to manage the risk of human activities. The risk of a specific system or process must be appropriately understood when making a reliable choice. Fuzzy logic is a novel mathematical technique for modelling the actual world's inaccuracy, uncertainty, and human thinking. This research highlights how fuzzy logic can be used to assess risk.

\subsection{Using fuzzy logic analysis for construction projects}

Risk analysis methods can be qualitative or quantitative (Bennett, 1996). Quantitative approaches are based on a statistical methodology. The Monte Carlo Simulation, Sensitivity Analysis (White, 1995), Risk Exposure, Annual Loss Expectancy, Failure Mode and Effective Analysis, Event Tree and Fault Analysis (Bennett, 1996) and other tools are traditional quantitative approaches used in the construction industry for risk assessment. Because these methods exclusively employ high-quality quantitative data required for the efficient use of these traditionally complex quantitative procedures (Zadeh, 2007), fuzzy set theory can assess risk based on a qualitative approach that relies on judgement rather than numerical calculations (Rainer Jr, 1991). Quantitative procedures can incur high costs and are only justified in cases where probability theory assumptions are met. Fuzzy set theory is suitable for risk assessment among these approaches because risk analysis in a construction project is hugely subjective and contains ambiguous and inexact data. One of the uses of fuzzy risk analysis in the construction research field is to establish a linguistic analytic method to analyse the risks of a construction project. In a fuzzy system, the parallel nature of rule activation guarantees that all the elements are evaluated in a coordinated manner. The outputs of fuzzy systems can be scaled to be comparable using scaling membership functions (Rainer Jr, 1991). Using linguistic sets and rules by fuzzy logic enables the user interface terminology and modelling structure to be customised to particular contexts. Thus, the risk analysis process, which employs fuzzy logic, has been proven to be the most effective method for dealing with project risk management, which is primarily subjective and varies significantly from project to project.

\subsection{Fuzzy logic Toolbox in MATLAB}

A fuzzy logic toolbox is created with the MATLAB numerical computing environment, which includes tools for creating and editing fuzzy inference systems. Alternatively, it uses Simulink to incorporate fuzzy systems into simulations. This toolkit largely depends on graphic user interface (GUI) features to assist in completing tasks, which work together to create an environment for designing, analysing, and implementing fuzzy inference systems. A set of blocks for use with the Simulink simulation programme is the third category of tools. These were created with Simulink in mind and are optimised for high-speed fuzzy logic inference.

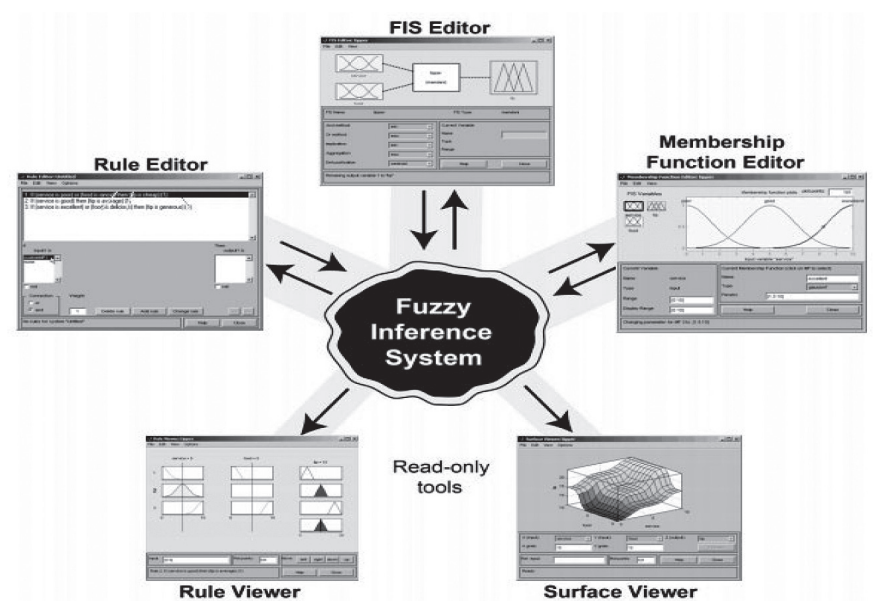

Fig. 1 Fuzzy Inference System

\section{LITERATURE REVIEW}

In the management and evaluation of risk, a substantial amount of research has been conducted. The risk is calculated in terms of its consequences and effects. Each industry creates a concept of risk by looking at it through its lens, resulting in a broad range of interpretations of what "risk" entails. As an example, (Al-Bahar, 1990) defined risk as "the risk of events occurring that have a negative or positive impact on project objectives as a result of uncertainty". (PMI, 2004) defines a project risk as an unforeseen incident or scenario that has a positive or negative influence on a project's aim if it occurs.

According to (Krane, 2010), risk is a fundamental determinant in guaranteeing a project's success, and risk management is an essential component of every capital project, particularly building projects. The risk may also be characterised as the impact of uncertainty on objectives (BS ISO 31000,2018 ), and the result might be favourable, adverse, or out of the ordinary. Also, the risk is sometimes characterised by an occurrence, a change in conditions, or a consequence.

(Tah, 2001) defined risk management as "a systematic approach of looking at areas of risk and actively selecting how each should be treated." It is a risk and uncertainty management technique that tries to advise appropriate management solutions and identify risk and uncertainty sources. Each risk has its features that require specific management or analysis. As the nature of the construction industry is very complex, a proper risk management plan should be implemented throughout the various phases of residential building projects in India. The objective of every firm 
is to succeed, and risk management may help them do so. Risk Management is not a methodology that assures success; instead, it is a tool that assists in raising the chances of success. As a result, rather than being reactive, risk management is proactive. Primary risk reactions may be discovered during the risk identification step in some situations. Identifying the key risk factors that affect a project's smooth completion is essential in risk management.

According to (El-Sayegh, 2008), attempting to identify all possible hazards for a building project is time-consuming, inefficient, and impractical. As a result, the emphasis should be placed on identifying the most essential and most often occurring hazards.

(Yong, 2012) Identified 37 elements that determine the success of a construction project, of which 15 critical risk factors for the success of a construction project in Malaysia were identified in their study; Therefore, risks may also be perceived to link to an opportunity or a failure or the existence of an organisation's instability.

(Bu-Qammaz, 2009) observed that by offering an insight into the nature of risks and their origins, organised risk categorisation seeks to enhance the efficacy and quality of the evaluation stage. (Zadeh, 1965) introduced the idea of a fuzzy system as a framework of an ambiguous reality. In construction project scheduling, (Ayyub, 1984) applied fuzzy set concepts. (Kangari 1989) presented a model for the evaluation of risk based on fuzzy set theory through the integration of the computation of natural languages, assessment of the risk of a fuzzy set, and linguistic approximation models. (Tah, 2000) also proposed a risk analysis model that used linguistic variables. (Cho, 2002) suggested a risk assessment approach that combined uncertainty with fuzzy notions within established risk assessment frameworks. (Shang, 2005) created a fuzzy-based risk model to evaluate risk probability and effects using linguistic parameters. (Nieto-Morote, 2011) presented risk modelling and analytic techniques based on fuzzy set theory to cope with ambiguous, indefinite, and complicated risk analysis issues. (White, 1995) evaluated the performance of building projects based on correlation using fuzzy set theory. (Manoliadis, 2018) used the concepts of fuzzy composition and fuzzy association to find correlations between risks and their impacts on project performance measurements. As a result, implementing consistent risk management processes and identifying the risk factors using a fuzzy logic toolbox within a comprehensive framework can assist in managing risks efficiently and effectively across an organisation.

\section{METHODOLOGY}

\subsection{Risk management}

Risk management is the process of detecting, analysing, and prioritising risks while simultaneously monitoring, controlling, and deploying organisational resources cost effectively to reduce the probability and/or impact of unfavourable occurrences and optimise the achievement of project objectives (Hubbard, 2020). Effective risk management can provide various benefits to the project manager, including improved chances of success, more exact estimates, greater confidence in accomplishing project objectives, fewer surprises, and less variations in resource usage (Bannerman, 2008). The construction industry has a reputation for being a high-risk industry, with complex and unpredictable project situations that create a high level of risk. Various technological, social, commercial, and other types of risks affect the construction sector. The construction industry has a poor track record, with countless

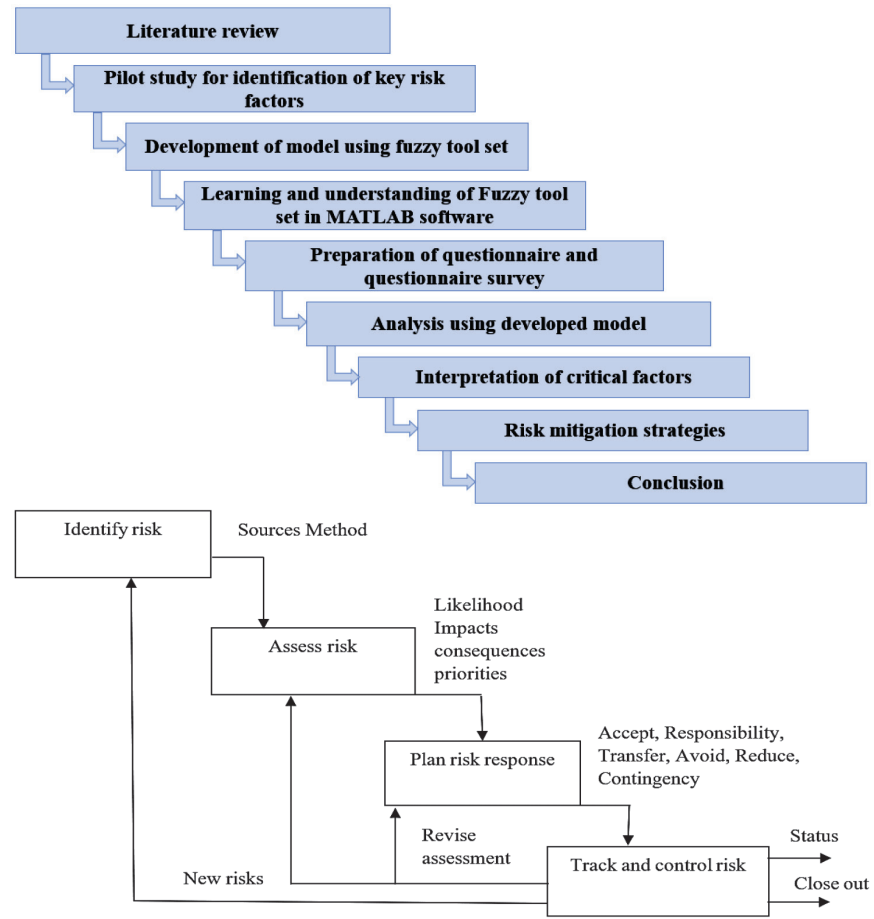

Fig. 2 Risk management elements and process (Nicholas, 2008)

projects failing to meet schedules, financial goals, and even the scope of the work when it comes to risk management.

Consequently, investors and contractors of such projects and the general public are subjected to a great deal of hardship. Practical risk management skills are required if the projects are completed on budget, on time, and meet quality requirements, because construction projects need a significant amount of time and money (Kangari, 1989). Projects can prevent unexpected and costly consequences by integrating risk management with project management, since resource allocation might be more effective; it increases communication and gives a clear assessment of potential hazards to the project, eventually assisting contractors in making better decisions (Kangari, 1989).

\subsection{Risk Identification}

Risks are frequently the outcome of uncertainties. When a project is surrounded by ambiguity, there is a marked lack of confidence in the future outcome; therefore, we can mitigate that uncertainty if we can detect where this uncertainty occurs. Checklists, brainstorming, breakdown of work structure, the use of professionals, the Delphi technique, past experience, and other methods are examples of identifying risk. Changes may be implemented with the least amount of interruption at this stage.

\subsection{Risk Assessment}

Risk assessment is used to determine and quantify the expected impact of any potential hazards. This evaluation process is divided into two parts. The first part is a qualitative assessment in which the source, origin, and effect of a possible danger are all examined and discussed in depth. This allows for the creation of a risk registry in which the state of each risk may be examined and updated regularly; it is the most crucial part of continual risk man- 
agement. The second part is a quantitative assessment in which the risk's potential impact is examined in-depth, as is its knock-on effect on the outcome of the project. The most likely and worstcase project outcomes may be estimated using such extensive analysis. In this study, the proposed fuzzy matrix has the benefit of allowing for qualitative risk event assessment.

\subsection{Risk Response and mitigate}

The issue of how to cope with risk is addressed in risk response planning. Transferring the risk, changing plans or processes to prevent or decrease the risk, preparing contingency plans or accepting the risk are all options for dealing with an identified risk. When deciding how to respond to danger, one must consider the cost of the recommended course of action.

\subsection{Track and control risk}

The risks are documented and put on a list known as a risk log or risk register, which ranks the highest risk consequences. Plans and methods for mitigating the risks and that set out are the most catastrophic implications are developed. The project should continually be examined for triggering indicators of previously known hazards and signs of new, unidentified risks. All critical and relevant risks should be tracked throughout the project or phases.

\section{DEVELOPMENT OF A MODEL}

In this section, a model of some construction techniques was developed for analysing the critical risk factors. Using fuzzy theory, the risk severity of factors affecting residential building construction projects is quantified using the model. As a result, certain fundamental concepts in the fuzzy inference process and fuzzy set theory are discussed herein, along with the details of the model prepared for assessing the severity of risk (Fuzzy Logic Toolbox ${ }^{\mathrm{TM}, 2015)}$.

\subsection{The fundamental notion of fuzzy set theory}

A fuzzy set $\mathrm{X}$ of a universe of discourse $\mathrm{Y}$ is defined by a membership function $\mathrm{X}(\mathrm{y})$ : $\mathrm{Y}[0,1]$ that takes values in the interval $[0,1]$, which is expressed as follows:

$$
\mathrm{X}=\{(\mathrm{y}, \mu \mathrm{X}(\mathrm{y})) / \mathrm{y} \in \mathrm{X}, \mu \mathrm{X}(\mathrm{y}) \in[0,1]\}
$$

where: $\mathrm{X}(\mathrm{y})$ is a membership function that expresses how meticulously each element of $\mathrm{y}$ in $\mathrm{X}$ belongs to the fuzzy set $\mathrm{X}$. This definition assigns the value $\mu \mathrm{X}(\mathrm{y})$ in the range 0 to 1 to each element $\mathrm{y}$ in $\mathrm{X}$.

\subsection{Fuzzy inference system}

The Fuzzy inference system is a method that uses fuzzy logic to convert a given input into an output. Two notable fuzzy inference methods are the Takagi-Sugeno Fuzzy Model and Mamdani Fuzzy Inference System. The Mamdani inference method is implemented this study for the preparation of the model; the phases used in this process are given below (Mamdani, 1975):

1. A set of the fuzzy rules is developed.

2. By establishing the membership functions, the crisp inputs are fuzzified.

3. The fuzzified inputs are mixed with the fuzzy rules to determine the rule strength.

4. The results are aggregated to produce an output distribution.

5. The output distribution is defuzzified to provide a crisp result.

\subsection{Defining input and output}

Two essential risk factors, i.e., risk probability and impact, are commonly used to quantify risk severity. As a result, the probability index and impact index for residential building risk factors are employed in this model as input variables. The output of this model is the severity of the risk, which is used to quantify its magnitude.

\subsection{Membership functions}

A membership function is a curve that represents the approximate number of linguistic variables in a range of 0 to 1 . It assigns each label a number value. Membership functions come in various forms, including triangular, trapezoidal, S-shaped, Z-shaped, Gaussian, piecewise-linear, bell-shaped, etc. Equation (1) below represents a triangular fuzzy number $\mathrm{z}$ with a membership function, as shown in Fig. 5.

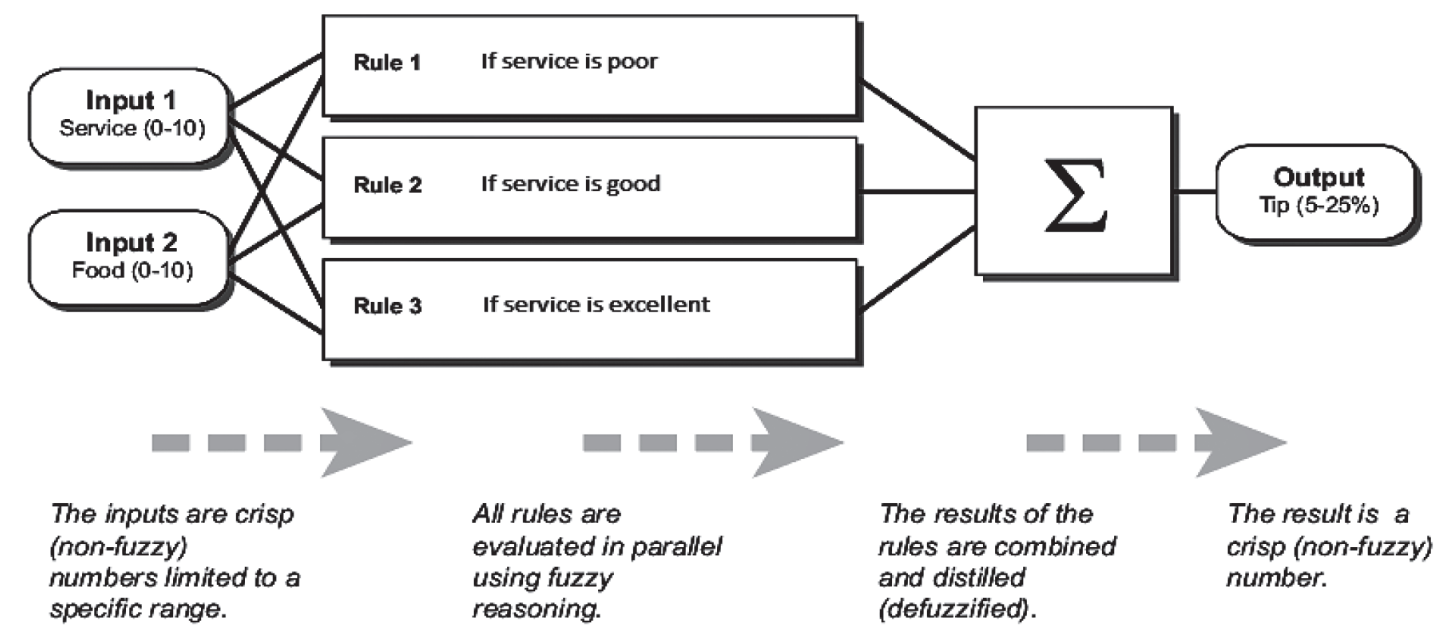

Fig. 3 Mamdani Inference System 


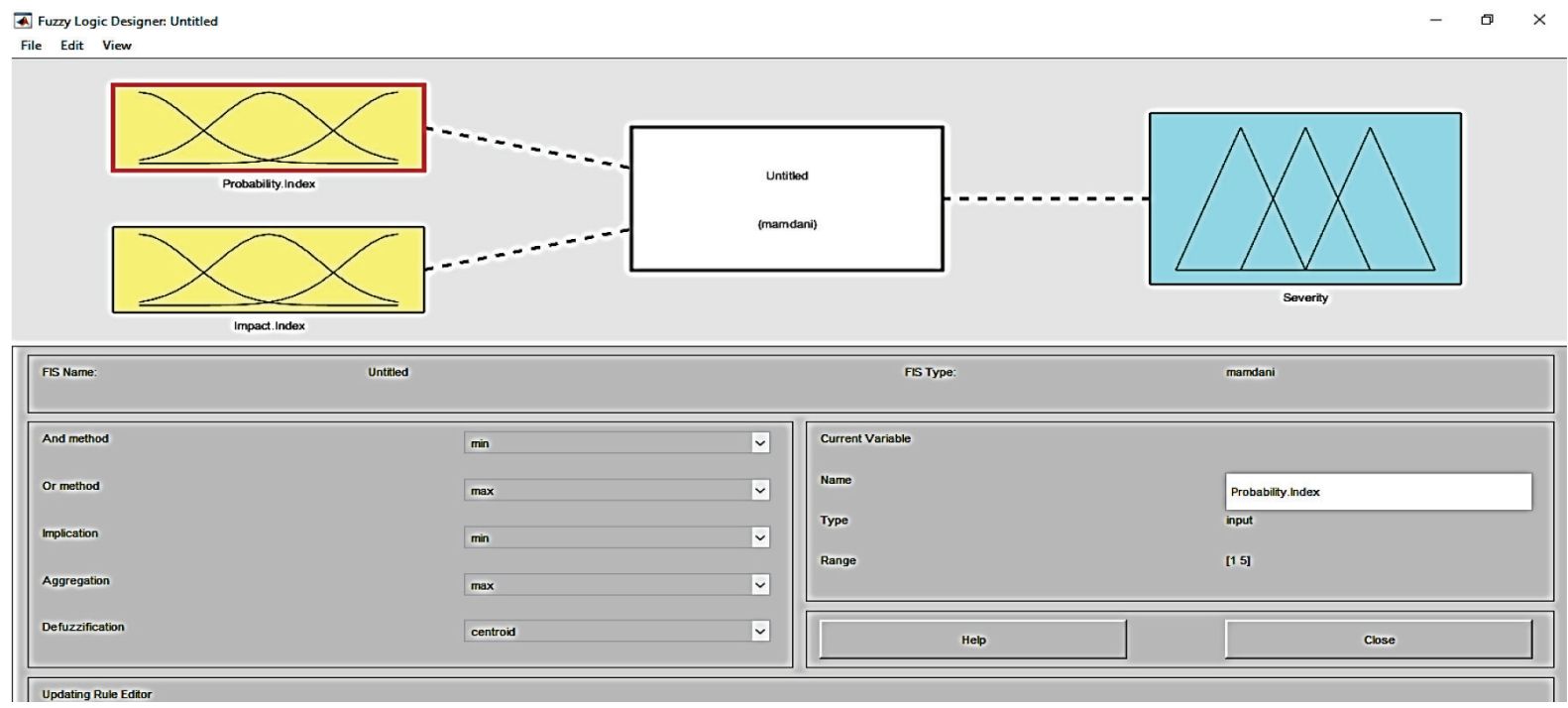

Fig. 4 Defining the input and output

$\mu X(z)=\left\{\begin{array}{ll}(z-x 1) / x m-x 1) & x 1 \leq z \leq x m \\ (x 2-z) /(x 2-x m) & x m \leq z \leq x 2\end{array}\right\}$

In this study, the triangular membership function was employed for the input and output variables. Five membership functions were assigned (Tab. 1) for the inputs; probability and impact indices, and four membership functions were assigned (Tab. 2) for the outputs' severity. Tabs. 1 and 2 display each linguistic variable's triangular fuzzy value, e.g., its probability, impact, or severity index. The membership function for these variables is graphically shown in Figs. 8, 9, and 10. The graphic representation of the rule base is shown in Fig. 11.

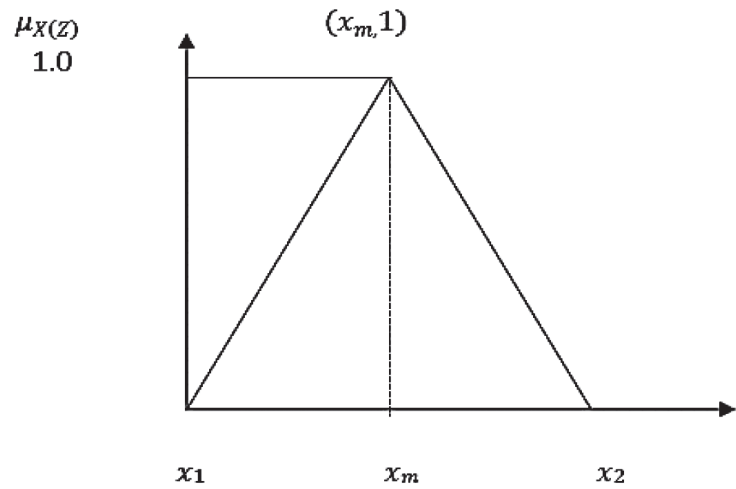

Fig. 5 Triangular membership function (Karimi, 2011)

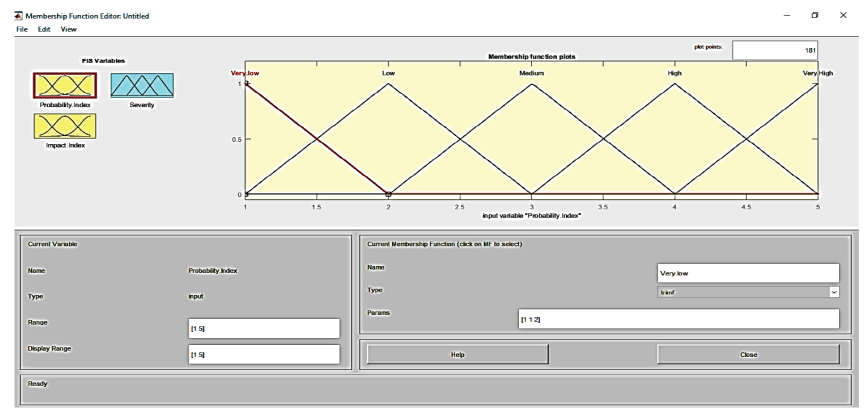

Fig. 6 Membership function of input

\subsubsection{Linguistic variable}

Fuzzy sets deal with degrees of truth and membership in a specific class. Fuzzy logic employs fuzzy rules to get desired outcomes from linguistic data or variables. The linguistic variable is a variable whose values are natural language sentences.

Tab. 1 Input linguistic variables

\begin{tabular}{cc}
\hline Fuzzy variable & Triangular number \\
\hline Lowest & $1,1,2$ \\
Low & $1,2,3$ \\
Moderate & $2,3,4$ \\
High & $3,4,5$ \\
Highest & $4,5,5$ \\
\hline
\end{tabular}

Tab. 2 Output of linguistic variables

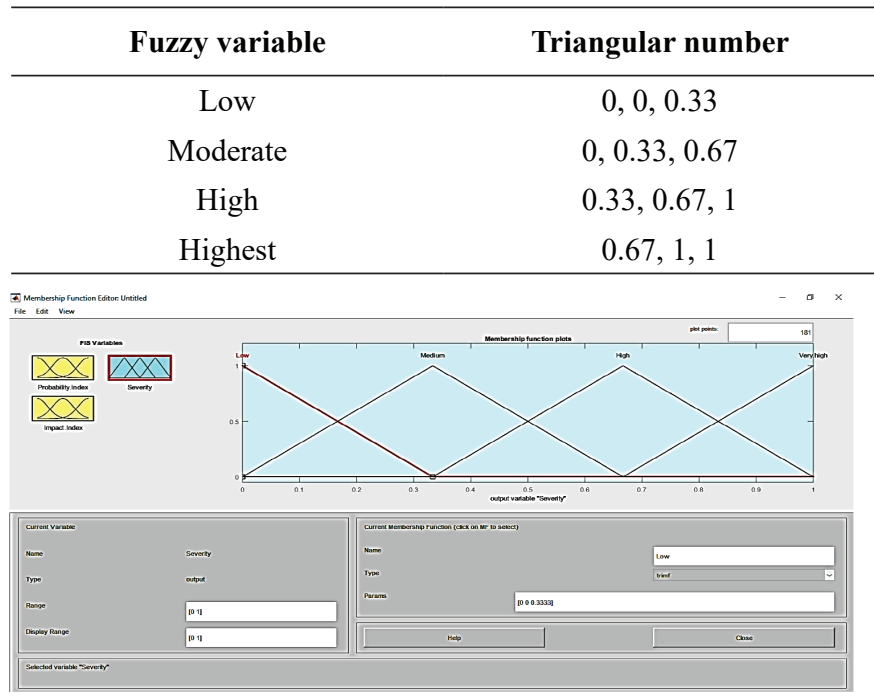

Fig. 7 Membership function of output 


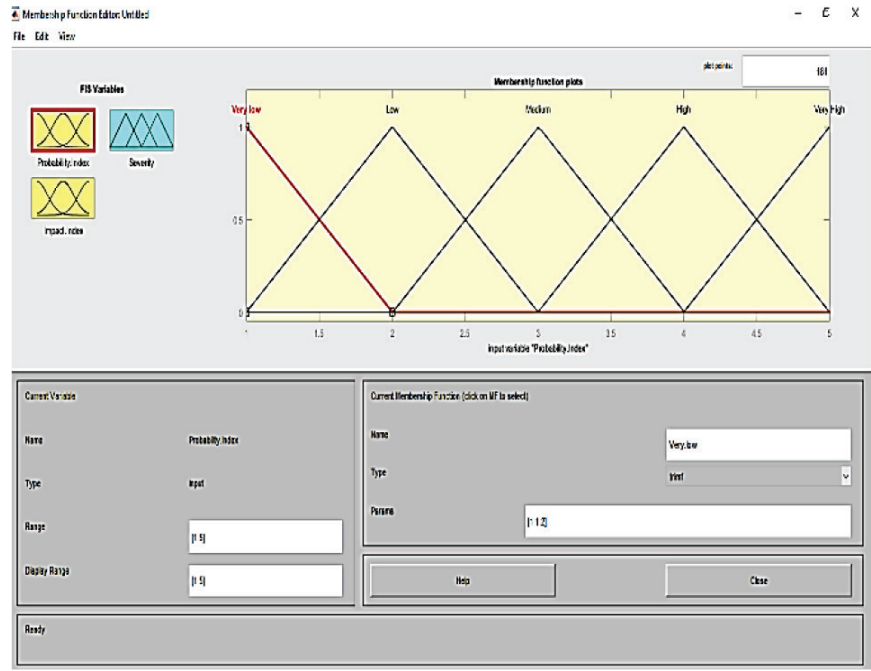

Fig. 8 Membership function of probability

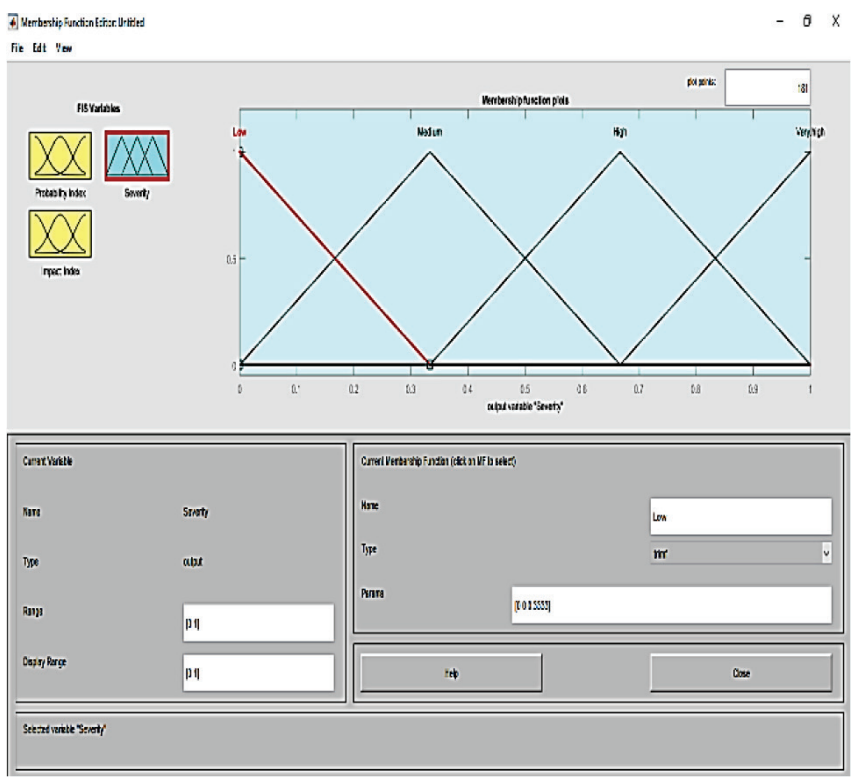

Fig. 10 Membership function of severity the index

\subsection{Formation of rules}

This study utilised the probability index and the impact index for the precursor part and the severity index for the subsequent part to find the magnitude of the risk factors, as shown in Fig. 10 Rules were formed to link the two inputs' probability and impact indices into one output severity index. Simple reasoning for the inputs, probability index, impact index, and output severity is required to link each element's parameters.

\subsubsection{Fuzzy operators}

To create fuzzy rules, the fuzzy operators "AND," "OR," and "NOT" are utilised. The following is an explanation of these "fuzzy combination" operators. Consider the two fuzzy sets X and $\mathrm{Y}$, each with $\mu \mathrm{x}(\mathrm{z})$ and $\mu \mathrm{y}(\mathrm{z})$ membership functions.

The intersection operation (equivalent to the logical "AND") is given by:

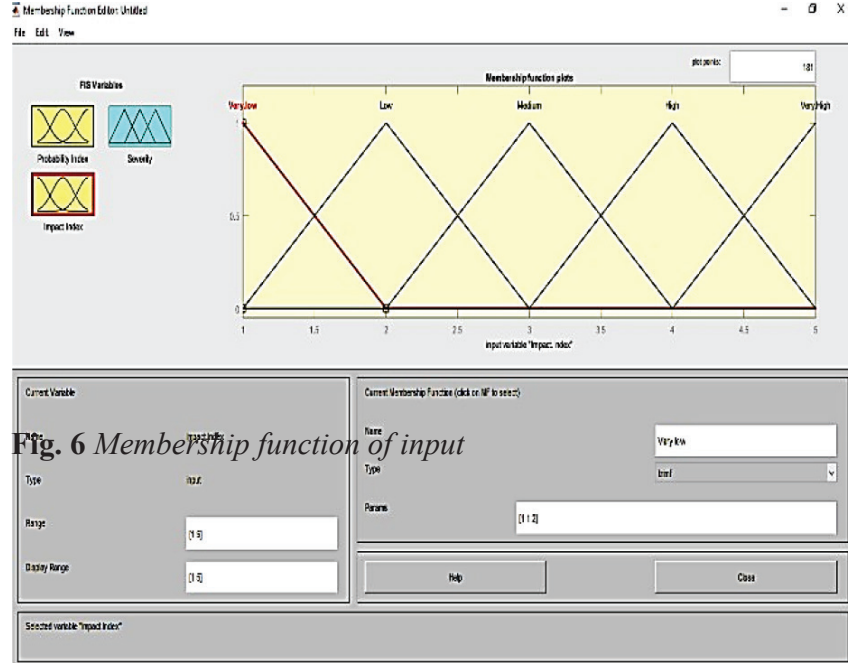

Fig. 9 Membership function of impact

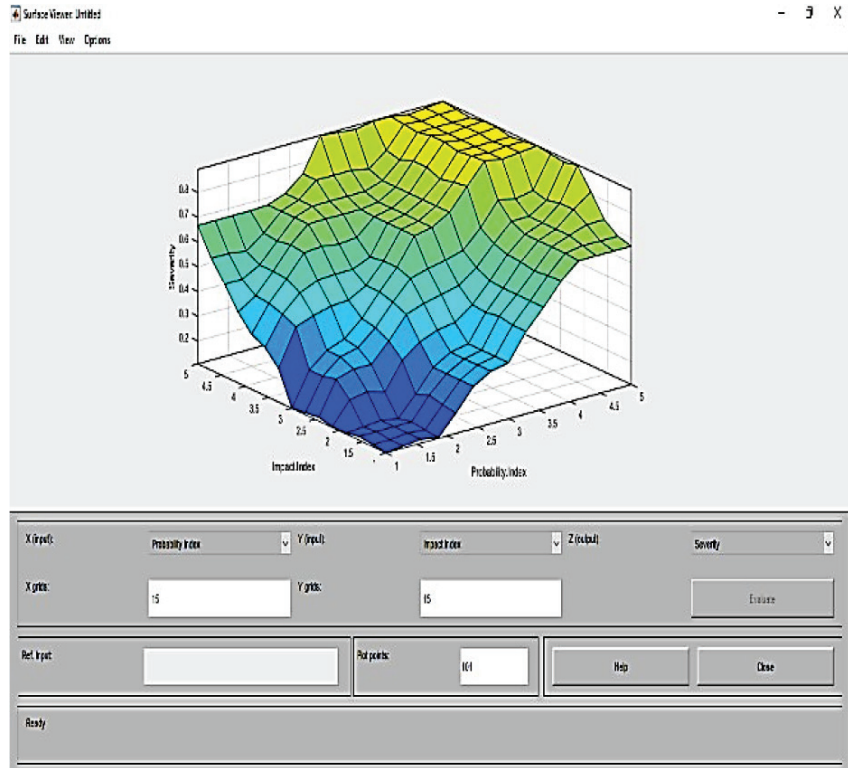

Fig. 11 Graphic representation of the rule base

$$
\mu \mathrm{X} \cap \mathrm{Y}(\mathrm{z})=\min [\mu \mathrm{X}(\mathrm{z}), \mu \mathrm{Y}(\mathrm{z})]
$$

The union operation (which is equivalent to the logical 'OR') is defined as:

$$
\mu \mathrm{XUY}(\mathrm{x})=\max [\mu \mathrm{X}(\mathrm{z}), \mu \mathrm{Y}(\mathrm{z})]
$$

\subsubsection{If-then rules}

A fuzzy logic system is a set of IF-THEN rules that link linguistic variables input to a final output value. Every fuzzy rule includes a preceding and a following rule, both of which have fuzzy theories. These theories, in turn, are assertions that use the language operators "and," "or," and "not" to connect the linguistic variables. While preparing a model in fuzzy logic most of the time, the linguistic operator "and" is used to link the precursor's linguistic categorisation, but the subsequent one is made of simply one language categorisation. As a result, if-then rules using the clamp "and" are applied in this study. The following relation 
(4) is used to explain the underlying premise of a fuzzy rule applied within the control systems of fuzzy logic:

$$
\text { If } \mathrm{z} 1 \text { is } \mathrm{X} 1 \mathrm{AND} \mathrm{z} 2 \text { is } \mathrm{X} 2 \text {, then } \mathrm{u} \text { is } \mathrm{Y}
$$

where the linguistic variables $\mathrm{z} 1$ and $\mathrm{z} 2$ input have fuzzy values of $\mathrm{X} 1$ and $\mathrm{X} 2$, and the linguistic variable output $\mathrm{u}$ has a fuzzy value of $\mathrm{Y}$.

\subsubsection{Risk matrix}

As indicated in Tab. 3, fuzzy values from the risk matrix are utilised to create a relationship between these parameters, which are taken from (PMI, 2004). There are five fuzzy sets in each of the two variables input. If the quantity of fuzzy sets given by $m$ expresses the probability index's variable input, and $n$ expresses the impact index's variable input, the possible quantity of the assertions represented is $m^{*} n$. As a result, there are a total of twenty-five rules in this study.

1. If the probability is highest and the impact is highest, then the degree of severity is highest.

2. If the probability is high and the impact is lowest, then the degree of severity is highest.

3. If the probability is moderate and the impact is highest, then the degree of severity is highest.

4. If the probability is low and the impact is highest, then the degree of severity is high.

5. If the probability is lowest and the impact is highest, then the degree of severity is high.

The rules as mentioned above were created in MATLAB Program Software's Fuzzy Logic Toolbox (the rule editor). It uses the rule editor to automatically build the rule statements based on the FIS Editor's definitions of the input and output variables.

Tab. 3 Risk matrix

\begin{tabular}{|c|c|c|c|c|c|}
\hline \multirow{2}{*}{$\begin{array}{c}\text { Fuzzy } \\
\text { variable }\end{array}$} & \multicolumn{5}{|c|}{ Probability Index } \\
\cline { 2 - 6 } & Highest & High & Moderate & Low & Lowest \\
\hline Lowest & Highest & Highest & Highest & High & High \\
\hline Low & Highest & Highest & High & High & Moderate \\
\hline Moderate & Highest & Highest & High & Moderate & Low \\
\hline High & Highest & High & Moderate & Low & Low \\
\hline Highest & High & High & Moderate & Low & Low \\
\hline
\end{tabular}

\subsection{Defuzzify}

The model then defuzzified the merged fuzzy output, yielding an output value. The intensity of the severity was evaluated as a distinct value between 0 and 1 . As demonstrated in Fig. 12, the complete procedure is represented in the Fuzzy Logic Toolbox's rule viewer window. The rule viewer depicts the entire fuzzy inference process in a visual form. It provides the ability to comprehend the whole process of fuzzy inference at the same time. The rule viewer also shows how the various membership function parameters impact the final results.

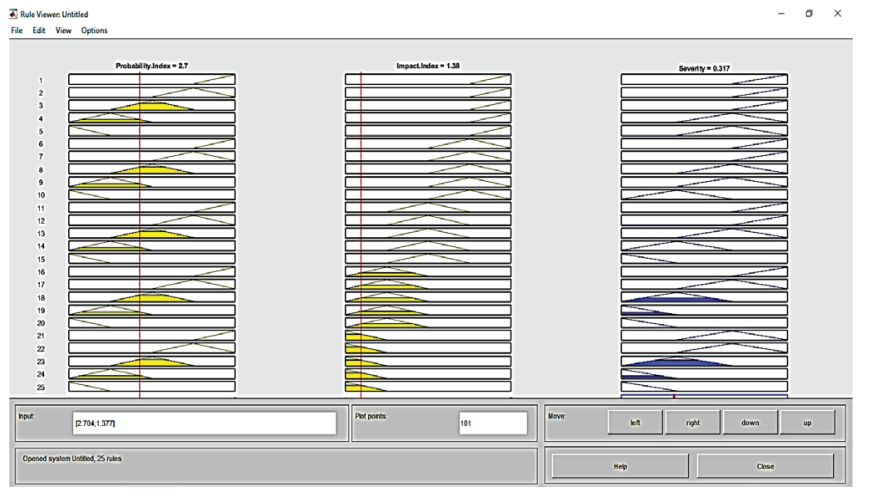

Fig. 12 Rule viewer

\section{APPLICATION OF THE MODEL DEVELOPED}

The conventional approach calculates the risk severity of the factor "location and size of the project". The "severity of the factor" location and the "size of the project" is calculated using the procedures below.

\subsection{Data collection}

Because of the significance of the problem of risk factors impacting construction projects, many research works that examined and explored the essential risk factors impacting construction projects were found in the literature review. A total of 60 risk factors were identified through an intensive literature review and the conducting of in-person interviews with professionals in the construction industry. Subsequently, a pilot survey was conducted to check the validity of the identified risk factors and eliminate the risk factors that are faced the least and have considerably less impact on residential building construction projects than other key risk factors. The experts were requested to suggest additional factors which were not on the list. These risk factors are classified into 7 major groups: construction, project manager, architect/ consultant, contractor, owner, resources, and external environment-specific risk factors. A questionnaire was prepared based on the risk factors identified. Data obtained through the pilot study was also used for the preparation of the central questionnaire survey. This questionnaire was sent to construction industry experts via mail, and data was also collected by interviewing construction industry experts in person. The questionnaire consisted of two parts: the first part consisted of the personal details of the respondents such as the name, email address, organisation's name, designation, and their experience in years, while the second section consisted of a technical part. The Likert scale was used to gather the data because it is very convenient for respondents to provide such data, and we could get as many answers as possible. The Likert scale is used to collect data for both the probability of an occurrence and the degree of the impact of a risk, ranging from one to five. For the respondent's numerical numbers, language values ascribed for the probability index and the impact index were: $1=$ Lowest, $2=$ Low, $3=$ Moderate, $4=$ High, $5=$ Highest. These linguistic variables were given the fuzzy values utilised in the constructed model. The prepared questionnaire was filled in by general managers, project managers, assistant engineers, and site engineers, as shown in Tab. 4; it was used for the final analysis of the risk factors. Cover letter was attached to the questionnaire 
so the respondents could know the proper purposes of the study. A total of 52 responses were received for this form, which can be considered a successful response. Tab. 5 provides the experts' responses as well as their respective fuzzy values.

\subsection{Cronbach alpha}

The Cronbach alpha test was carried out to check the reliability of the data collected through the questionnaire. If its value is greater than 0.7 , then the data collected through the questionnaire is considered reliable. The Cronbach alpha value obtained for the probability is 0.93 and 0.91 for the impact. Therefore, the data collected through the questionnaire is reliable and is used further for the fuzzy analysis.

Tab. 4 Number of responses and experience

\begin{tabular}{|c|c|c|c|}
\hline Sr. No. & Designation & No. & Experience (Years) \\
\hline 1 & General Manager & 3 & More than 20 \\
\hline 2 & Project Manager & 18 & More than 20 \\
\hline 3 & Assistant Engineer & 18 & $5-15$ \\
\hline 4 & Site Engineer & 13 & $3-5$ \\
\hline
\end{tabular}

\subsection{Average using the fuzzy toolbox}

The fuzzy averaging process for the aggregate method, which is also called the Triangular Average Formula, was employed (Bojadziev, 2007).

For $\mathrm{n}$ number of experts, the triangular average formula is considered a fuzzy number, and $\mathrm{n}$ is the experts' group.

$$
\mathrm{X}_{\mathrm{i}=}\left(\mathrm{x}_{1}^{(\mathrm{i})}, \mathrm{x}_{\mathrm{m}}{ }^{(\mathrm{i})}, \mathrm{x}_{2}^{(\mathrm{i})}\right), \mathrm{i}=1,2,3 \ldots \mathrm{n}
$$

The average fuzzy numbers, i.e., $\mathrm{X}_{1}$ and $\mathrm{X}_{2}$, were determined as follows:

$$
\begin{gathered}
\left(\mathrm{X}_{1}+\mathrm{X}_{2}\right) / 2=\left[\left(\mathrm{x}_{1}^{(1)}+\mathrm{x}_{\mathrm{m}}^{(1)}+\mathrm{x}_{2}^{(1)}\right)+\left(\mathrm{x}_{1}^{(2)}+\mathrm{x}_{\mathrm{m}}^{(2)}+\mathrm{x}_{2}^{(2)}\right)\right] / 2 \\
\left(\left(\mathrm{x}_{1}^{(1)}+\mathrm{x}_{1}^{(2)}\right),\left(\mathrm{x}_{\mathrm{m}}^{(1)}+\mathrm{x}_{\mathrm{m}}^{(2)}\right),\left(\mathrm{x}_{2}^{(1)}+\mathrm{x}_{2}^{(2)}\right)\right) / 2
\end{gathered}
$$

The average of $\mathrm{n}$ fuzzy numbers may be determined using the following formula (6):

$$
\begin{gathered}
\mathrm{X}_{\text {average }}=\mathrm{X} 1+\ldots \mathrm{Xn} / \mathrm{n} \\
\mathrm{X}_{\text {average }}=\left(\left(\mathrm{X}_{1}^{(1)}+\mathrm{X}_{\mathrm{m}}^{(1)}+\mathrm{X}_{2}^{(1)}\right)+\ldots\left(\mathrm{X}_{1}^{(\mathrm{n})}+\mathrm{X}_{\mathrm{m}}^{(\mathrm{n})}+\mathrm{X}_{2}^{(\mathrm{n})}\right)\right) / \mathrm{n}
\end{gathered}
$$

using the equation given above for the probability index and impact index.

The fuzzy values are derived as follows:

For the probability index the average fuzzy value $=(1.807$, 2.653, 3.653) 3.634)

For the impact index the average fuzzy value $=(1.711,2.634$,

The fuzzy value $(\mathrm{x} 1, \mathrm{xm}, \mathrm{x} 2)$ was translated into the greatest non-fuzzy performance (GNP) value to generate a crisp value, us-

\begin{tabular}{|c|c|c|c|c|}
\hline Response & $\begin{array}{l}\text { Probability } \\
\text { Index }\end{array}$ & $\begin{array}{l}\text { Impact } \\
\text { Index }\end{array}$ & $\begin{array}{c}\text { Fuzzy Value } \\
\text { of Probability } \\
\text { Index }\end{array}$ & $\begin{array}{l}\text { Fuzzy Value of } \\
\text { Impact Index }\end{array}$ \\
\hline 1 & 3 & 2 & $2,3,4$ & $1,2,3$ \\
\hline 2 & 3 & 4 & $2,3,4$ & $3,4,5$ \\
\hline 3 & 1 & 1 & $1,1,2$ & $1,1,2$ \\
\hline 4 & 3 & 2 & $2,3,4$ & $1,2,3$ \\
\hline 5 & 5 & 4 & $4,4,5$ & $3,4,5$ \\
\hline 6 & 3 & 4 & $2,3,4$ & $3,4,5$ \\
\hline 7 & 5 & 5 & $4,4,5$ & $4,4,5$ \\
\hline 8 & 3 & 3 & $2,3,4$ & $2,3,4$ \\
\hline 9 & 2 & 3 & $1,2,3$ & $2,3,4$ \\
\hline 10 & 2 & 3 & $1,2,3$ & $2,3,4$ \\
\hline 11 & 3 & 3 & $2,3,4$ & $2,3,4$ \\
\hline 12 & 3 & 3 & $2,3,4$ & $2,3,4$ \\
\hline 13 & 3 & 3 & $2,3,4$ & $2,3,4$ \\
\hline 14 & 4 & 3 & $3,4,5$ & $2,3,4$ \\
\hline 15 & 4 & 4 & $3,4,5$ & $3,4,5$ \\
\hline 16 & 2 & 1 & $1,2,3$ & $1,1,2$ \\
\hline 17 & 2 & 2 & $1,2,3$ & $1,2,3$ \\
\hline 18 & 3 & 4 & $2,3,4$ & $3,4,5$ \\
\hline 19 & 4 & 2 & $3,4,5$ & $1,2,3$ \\
\hline 20 & 3 & 2 & $2,3,4$ & $1,2,3$ \\
\hline 21 & 3 & 2 & $2,3,4$ & $1,2,3$ \\
\hline 22 & 3 & 2 & $2,3,4$ & $1,2,3$ \\
\hline 23 & 4 & 2 & $3,4,5$ & $1,2,3$ \\
\hline 24 & 3 & 1 & $2,3,4$ & $1,1,2$ \\
\hline 25 & 4 & 4 & $3,4,5$ & $3,4,5$ \\
\hline 26 & 2 & 2 & $1,2,3$ & $1,2,3$ \\
\hline 27 & 2 & 3 & $1,2,3$ & $2,3,4$ \\
\hline 28 & 3 & 2 & $2,3,4$ & $1,2,3$ \\
\hline 29 & 3 & 2 & $2,3,4$ & $1,2,3$ \\
\hline 30 & 3 & 2 & $2,3,4$ & $1,2,3$ \\
\hline 31 & 4 & 3 & $3,4,5$ & $2,3,4$ \\
\hline 32 & 2 & 3 & $1,2,3$ & $2,3,4$ \\
\hline 33 & 3 & 3 & $2,3,4$ & $2,3,4$ \\
\hline 34 & 2 & 3 & $1,2,3$ & $2,3,4$ \\
\hline 35 & 3 & 2 & $2,3,4$ & $1,2,3$ \\
\hline 36 & 2 & 3 & $1,2,3$ & $2,3,4$ \\
\hline 37 & 3 & 3 & $2,3,4$ & $2,3,4$ \\
\hline 38 & 2 & 3 & $1,2,3$ & $2,3,4$ \\
\hline 39 & 2 & 3 & $1,2,3$ & $2,3,4$ \\
\hline 40 & 2 & 2 & $1,2,3$ & $1,2,3$ \\
\hline 41 & 3 & 2 & $2,3,4$ & $1,2,3$ \\
\hline 42 & 3 & 4 & $2,3,4$ & $3,4,5$ \\
\hline 43 & 1 & 3 & $1,1,2$ & $2,3,4$ \\
\hline 44 & 1 & 2 & $1,1,2$ & $1,2,3$ \\
\hline 45 & 4 & 2 & $3,4,5$ & $1,2,3$ \\
\hline 46 & 1 & 2 & $1,1,2$ & $1,2,3$ \\
\hline 47 & 1 & 3 & $1,1,2$ & $2,3,4$ \\
\hline 48 & 2 & 2 & $1,2,3$ & $1,2,3$ \\
\hline 49 & 1 & 2 & $1,1,2$ & $1,2,3$ \\
\hline 50 & 2 & 2 & $1,2,3$ & $1,2,3$ \\
\hline 51 & 3 & 4 & $2,3,4$ & $3,4,5$ \\
\hline 52 & 2 & 2 & $1,2,3$ & $1,2,3$ \\
\hline
\end{tabular}
ing the following formula (8):

$$
\left(\left(x_{2}-x_{1}\right)+\left(x_{m}-x_{1}\right)\right) / 3+x 1
$$

Tab. 5 Responses for the "location and size of the project" risk factor 
Tab. 6 Fuzzy output for each risk factor

\begin{tabular}{|c|c|c|}
\hline RISK FACTORS & Fuzzy Output Risk Severity & Rank \\
\hline \multicolumn{3}{|l|}{ A. Specific construction risk factors } \\
\hline 1. Location and size of the project & 0.317 & 57 \\
\hline 2. Unsafe working conditions & 0.624 & 28 \\
\hline 3. Regulatory approval & 0.722 & 9 \\
\hline 4. Legal disputes & 0.449 & 42 \\
\hline 5. Labour accidents & 0.428 & 49 \\
\hline 6. Financial flow & 0.646 & 24 \\
\hline 7. Conflicts between actual and contract quantities & 0.438 & 46 \\
\hline 8. Unavoidable changes in climate & 0.402 & 50 \\
\hline 9. Unknown site conditions & 0.677 & 17 \\
\hline 10. Changes made at the request of the client & 0.655 & 23 \\
\hline 11. Improper planning of construction activities & 0.728 & 8 \\
\hline 12. No clear scope of project at the beginning & 0.783 & 3 \\
\hline 13. Improper construction methods & 0.696 & 12 \\
\hline \multicolumn{3}{|l|}{ B. Project manager specific risk factors } \\
\hline 1. Technical capability of project manager & 0.659 & 22 \\
\hline 2. Lack of leadership quality & 0.603 & 33 \\
\hline 3. Use of inappropriate planning tools and techniques by a project manager & 0.549 & 34 \\
\hline 4. Project manager's chances of leaving the project & 0.293 & 59 \\
\hline 5. Lack of coordinating ability & 0.722 & 9 \\
\hline 6. Holding key decisions in abeyance & 0.388 & 51 \\
\hline 7. Top management is not adhering to the targeted timeline. & 0.617 & 31 \\
\hline 8. Lack of training in human resources & 0.621 & 29 \\
\hline \multicolumn{3}{|l|}{ C. Architect \& Consultant specific risk factors } \\
\hline 1. Prior to the design, inadequate data collecting and surveying & 0.754 & 6 \\
\hline 2. Drawings with unclear and insufficient information & 0.455 & 40 \\
\hline 3. Insufficient involvement of a consultant & 0.450 & 41 \\
\hline 4. Design changes & 0.776 & 5 \\
\hline 5. Replacement of consultant & 0.248 & 60 \\
\hline 6. Consultant's failure to conduct inspections and tests on time & 0.687 & 14 \\
\hline 7. Complex/non-executable design & 0.513 & 36 \\
\hline 8. Inflexibility of consultant & 0.605 & 32 \\
\hline \multicolumn{3}{|l|}{ D. Contractor specific risk factors } \\
\hline 1. Chances of facing a financial crisis & 0.640 & 25 \\
\hline 2. Putting off important choices & 0.384 & 52 \\
\hline 3. Delay in mobilisation & 0.431 & 48 \\
\hline 4. Contractor oversight and site management are inadequate & 0.446 & 43 \\
\hline 5. Work by a subcontractor is behind schedule & 0.685 & 15 \\
\hline 6. Poor qualifications or experience of the contractor & 0.442 & 45 \\
\hline 7. Improper construction methods/quality variations. & 0.666 & 20 \\
\hline \multicolumn{3}{|l|}{ E. Owner specific risk factors } \\
\hline 1. Financial problems of the owner & 0.691 & 13 \\
\hline 2. Unreasonably high expectations of the owner & 0.373 & 54 \\
\hline 3. Payment delays by the owner & 0.785 & 2 \\
\hline 4. During construction, changes made by the owner & 0.664 & 21 \\
\hline 5. Delay in handing the site to the contractor & 0.355 & 56 \\
\hline 6. Inefficient decision making & 0.364 & 55 \\
\hline
\end{tabular}




\begin{tabular}{|c|c|c|}
\hline RISK FACTORS & Fuzzy Output Risk Severity & Rank \\
\hline \multicolumn{3}{|l|}{ F. Resources specific risk factors } \\
\hline $\begin{array}{l}\text { 1. Equipment shortage } \\
\text { 2. Equipment quality } \\
\text { 3. Selection of inappropriate equipment } \\
\text { 4. Delay in delivery of materials } \\
\text { 5. Changes in quality of material during execution } \\
\text { 6. Lack of specialised staff } \\
\text { 7. Shortage of labourers } \\
\text { 8. Low labour productivity } \\
\text { 9. Resource management } \\
\text { 10. Supply of defective material }\end{array}$ & $\begin{array}{l}0.515 \\
0.703 \\
0.678 \\
0.632 \\
0.627 \\
0.739 \\
0.670 \\
0.457 \\
0.788 \\
0.300\end{array}$ & $\begin{array}{c}35 \\
11 \\
16 \\
26 \\
27 \\
7 \\
19 \\
39 \\
1 \\
58 \\
\end{array}$ \\
\hline \multicolumn{3}{|l|}{ G. External environment-specific risk factors } \\
\hline $\begin{array}{l}\text { 1. Changing government policies } \\
\text { 2. Force majeure } \\
\text { 3. Labour strikes } \\
\text { 4. Unfavourable social environment } \\
\text { 5. Unfavourable political environment } \\
\text { 6. Escalation of material prices }\end{array}$ & $\begin{array}{l}0.675 \\
0.438 \\
0.618 \\
0.468 \\
0.381 \\
0.782\end{array}$ & $\begin{array}{c}18 \\
46 \\
30 \\
37 \\
53 \\
4\end{array}$ \\
\hline
\end{tabular}

The probability index's greatest non-fuzzy value $=2.704$.

The impact index's greatest non-fuzzy value $=1.377$.

The severity of the location and size of the project risk factors using probability index and impact index $=0.317$ (See Fig. 12).

Similarly, the risk severity of the other components was estimated based on the expert responses to the probability and impact indexes. The risk severity of the other factors affecting residential building construction projects in India is shown in Tab 6. The fuzzy output risk severity is ranked in all the seven major groups in descending order.

\section{OBSERVATIONS}

While conducting the study, it was discovered that various fuzzy logic models are available for construction projects. However, we created a basic fuzzy logic model that supported proper risk assessment because there was no adequate fuzzy logic model for residential building construction projects. The risk factors differ from one project to the next. As a result, the word "risk" is very subjective and dependent on the project's execution team. To put it another way, the degree of risk in a project varies depending on the contract's participants. Hence, in this study, all the risk factors are categorised into 7 major groups: construction, project manager, architect, consultant, contractor, owner, resources, and external environment-specific risk factors. The risk factors are assessed using a fuzzy toolbox in MATLAB software and ranked in descending order, considering each risk factor's fuzzy output risk severity. It distinguishes between factors with a high level of influence on a project and those with a low level of influence or between extremely vital and extremely insignificant factors. The ten most highly important and least important ten factors are listed below. Tab. 7 shows the ten most highly important factors with a high fuzzy output risk severity impacting project success. The top ten most important risk factors affecting residential building construction projects in India were computed using a fuzzy model based on the probability index and impact index, which includes resource management, payment delays by the owner, no clear scope of the project in the beginning, escalation of material prices, design changes, inadequate data collection and surveying prior to the design, lack of specialised staff, improper planning of construction activities, regulatory approval, and lack of the coordinating ability of the project manager. Tab. 8 shows the ten least important factors having the least fuzzy output risk severity.

Tab. 7 Highly severe factors

\begin{tabular}{|l|c|c|}
\hline RISK FACTORS & Fuzzy Output Risk Severity & Rank \\
\hline 1. Resource management & 0.788 & 1 \\
2. Payment delays by owner & 0.785 & 2 \\
3. No clear scope of project at the beginning & 0.783 & 3 \\
4. Escalation of material prices & 0.782 & 4 \\
5. Design changes & 0.776 & 5 \\
6. Inadequate data collection and surveying prior to design & 0.754 & 6 \\
7. Lack of specialised staff & 0.739 & 7 \\
8. Improper planning of construction activities & 0.728 & 8 \\
9. Regulatory approval & 0.722 & 9 \\
10. Lack of coordinating ability & 0.722 & 9 \\
\hline
\end{tabular}


Tab. 8 Least severe factors

\begin{tabular}{|l|c|c|}
\hline \multicolumn{1}{|c|}{ RISK FACTORS } & Fuzzy Output Risk Severity & Rank \\
\hline 1. Replacement of consultant & 0.248 & 60 \\
2. Project manager's chances of leaving the project & 0.293 & 59 \\
3. Supply of defective material & 0.300 & 58 \\
4. Location and size of the project & 0.317 & 57 \\
5. Delay in over hand of the construction site to the contractor & 0.355 & 56 \\
6. Owner inefficient in decision making & 0.364 & 55 \\
7. Unreasonable expectations of the owner & 0.373 & 54 \\
8. Unfavourable political environment & 0.381 & 53 \\
9. Contractor putting off important choices & 0.384 & 52 \\
10. Project manager holding critical decisions in abeyance & 0.388 & 51 \\
\hline
\end{tabular}

The low fuzzy output risk severity shows that such factors have a low impact on a project's success. As a result, a substantial risk response strategy is necessary for the highly severe risk factors.

\section{CONCLUSION}

The focus of the study was to identify the most crucial risk factors affecting the construction projects of residential buildings in India. The study mainly contributed to ranking the key risk factors by evaluating their probability of occurrence and impact in the fuzzy logic toolbox in MATLAB software. Because the theory can deal with ambiguity, uncertainty, and the subjective aspects of any circumstance, this study also provides a unique fuzzy-based way to evaluate the risk severity of diverse risk factors. This methodology ultimately supports the categorising and the prioritising of all risk factors based on their probability of occurrence and degree of impact, leading to improved decision making. Hence, the study mainly contributes to ranking the key risk factors by assessing their probability of occurrence and the degree of impact in the fuzzy logic toolbox in MATLAB software. The capacity of the fuzzy system to deal with ambiguous details and clarify the reasoning process has made it possible to assess risk in this study. This study proposes a fuzzy risk assessment methodology for residential building construction projects in India, which can help project managers to implement a risk evaluation methodology and risk response strategy for the most severe risks identified by the fuzzy evaluation model for the smooth completion of a project. The top ten identified risk factors affecting construction projects of residential buildings are: resource management, payment delays by the owner, no clear scope of project in the beginning, escalation of material prices, design changes, inadequate data collection and surveying prior to the design, lack of specialised staff, improper planning of construction activities, regulatory approval, and lack of coordinating ability of the project manager. As a result, for the top severe risk factors identified and a significant risk response strategy was implemented. 


\section{REFERENCES}

Abd El Khalek, - Hamada M. Kamel (2016) "Risk and uncertainty assessment model in construction projects using fuzzy logic." American Journal of Civil Engineering, pp. 24-39.

Al-Bahar, Jamal F., - Keith C. Crandall (1990) "Systematic risk management approach for construction projects." Journal of Construction Engineering and Management, pp. 533-546.

Ayyub, Bilal M., - Achintya Haldar (1984) "Project scheduling using fuzzy set concepts." Journal of Construction Engineering and Management, pp. 189-204.

Banaitiene, Nerija, - Audrius Banaitis (2012) "Risk management in construction projects." Risk Management-Current Issues and Challenges. In N. Banaitiene (Ed.), Risk Management-Current Issues and Challenges, pp. 429-448.

Bannerman, Paul L. (2008) "Risk and risk management in software projects: A reassessment." Journal of Systems and Software, pp. 2118-2133.

Bennett, Joanna C., et al. (1996) "Risk analysis techniques and their application to software development." European Journal of Operational Research, pp. 467-475.

Bojadziev, George, - Maria Bojadziev (2007) Fuzzy logic for business, finance, and management. Vol. 23. World Scientific, pp. 252.

BS ISO 31000 (2018) "Risk management - Guidelines". The British Standards Institute.

Bu-Qammaz, - M. Talat Birgonul (2009) "Risk assessment of international construction projects using the analytic network process." Canadian Journal of Civil Engineering, pp. 1170-1181.

Cho, Yoon-Bae Kim (2002) “A risk assessment methodology for incorporating uncertainties using fuzzy concepts." Reliability Engineering \& System Safety, pp. 173-183.

El-Sayegh, Sameh Monir (2008) "Risk assessment and allocation in the UAE construction industry." International journal of project management, pp. 431-438.

Fuzzy Logic ToolboxTM (2015) 2 user's guides, MATLAB. The Math Works, Inc., Natick.

Gunduz, - Mustafa Ozdemir (2015) "Fuzzy assessment model to estimate the probability of delay in Turkish construction projects." Journal of Management in Engineering, pp. 01-32.

Hubbard, Douglas W. (2020) The failure of risk management: Why it's broken and how to fix it. John Wiley \& Sons.

Kangari, - Leland S. Riggs (1989) "Construction risk assessment by linguistics." IEEE transactions on engineering management, pp. 126-131.

Karimi Azari - Amir Reza, et al. (2011) "Risk assessment model selection in construction industry." Expert Systems with Applications, pp. 9105-9111.

Koehn, E. (1984) "Fuzzy sets in construction engineering." Proc. CIB W-65.

Krane, Nils OE Olsson (2010) "Categorising risks in seven large projects-Which risks do the projects focus on?" Project management journal, pp. 81-86.
Mamdani - Sedrak Assilian (1975) "An experiment in linguistic synthesis with a fuzzy logic controller." International journal of man-machine studies, pp. 1-13.

Manoliadis, Odysseas (2018) “The assessment of construction project risks with the use of fuzzy Delphi methodology - case study photovoltaic project in Greece." International Journal of Management and Fuzzy Systems, pp. 7-14.

Nicholas, John M., - Herman Steyn (2008) Project management for business, engineering, and technology: principles and practice. Elsevier.

Nieto-Morote, - Francisco Ruz-Vila (2011) "A fuzzy approach to construction project risk assessment." International Journal of Project Management, pp. 220-231.

PMI A guide to the project management body of knowledge (2004) $P M B O K$ Guide, 3rd edn. Project Management Institute Inc., Newtown Square.

Rainer Jr, - Houston H. Carr (1991) "Risk analysis for information technology." Journal of Management information systems, pp. 129-147.

Shang, Huiping, et al. (2005) “An intelligent risk assessment system for distributed construction teams." Engineering, Construction and Architectural Management Vol. 12 Issue 4, pp. 391 - 409.

Subramanyan, - Vandana Bhatt (2012) "Construction project risk assessment: development of model based on investigation of opinion of construction project experts from India." Journal of construction engineering and management, pp. 409-421.

Tah, Joseph HM, - V. Carr (2000) "A proposal for construction project risk assessment using fuzzy logic." Construction Management \& Economics, pp. 491-500.

Tah, Joseph HM, - V. Carr (2001) "Knowledge-based approach to construction project risk management." Journal of computing in civil engineering, pp. 170-177.

V. T. Covello, - J. Mumpower (1986) Risk Evaluation and Management. New York: Plenum.

White, Diana (1995) “Application of systems thinking to risk management." Management Decision Vol. 33 No. 10, pp. 35-45.

Yeung, - Daniel WM Chan (2012) "Fuzzy set theory approach for measuring the performance of relationship-based construction projects in Australia." Journal of management in engineering, pp. 181-192.

Yong, - Nur Emma Mustaffa (2012) "Analysis of factors critical to construction project success in Malaysia." Engineering, construction and architectural management.

Zadeh, L.A. (1965) Fuzzy sets. Inf. Control 8(3), pp. 338-353.

Zadeh, L.A. (2007) "Application of a fuzzy based decision-making methodology to construction project risk assessment." International journal of project management, pp. 589-600. 